University of Nebraska - Lincoln

DigitalCommons@University of Nebraska - Lincoln

Faculty Publications, Department of Psychology

Psychology, Department of

March 1987

\title{
Maternal and Nutritional Contributions to Infant Rats'Activational Responses to Ingestion
}

\author{
Brian H. Bornstein \\ University of Nebraska-Lincoln, bbornstein2@unl.edu \\ Leslie M. Terry \\ Duke University, Durham, North Carolina \\ Joseph A. Browde Jr. \\ Duke University, Durham, North Carolina
}

Follow this and additional works at: https://digitalcommons.unl.edu/psychfacpub

Part of the Psychiatry and Psychology Commons

Bornstein, Brian H.; Terry, Leslie M.; and Browde, Joseph A. Jr., "Maternal and Nutritional Contributions to Infant Rats'Activational Responses to Ingestion" (1987). Faculty Publications, Department of Psychology. 209.

https://digitalcommons.unl.edu/psychfacpub/209

This Article is brought to you for free and open access by the Psychology, Department of at DigitalCommons@University of Nebraska - Lincoln. It has been accepted for inclusion in Faculty Publications, Department of Psychology by an authorized administrator of DigitalCommons@University of Nebraska - Lincoln. 


\title{
Maternal and Nutritional Contributions to Infant Rats' Activational Responses to Ingestion
}

\author{
Brian H. Bornstein \\ Leslie M. Terry \\ Joseph A. Browde, Jr. \\ Department of Psychology \\ Duke University \\ Durham, North Carolina \\ Sue Ann Assimon \\ Department of Psychology \\ University of Massachusetts, Amherst \\ Amherst, Massachusetts \\ W. G. Hall \\ Department of Psychology \\ Duke University \\ Durham, North Carolina
}

Submitted for publication January 1986; revised for publication May 1986.

Infant rats deprived of food, maternal care, and the opportunity to suckle display a dramatic behavioral activation and vigorously ingest when provided milk through oral cannulas. These experiments assessed which components of deprivation are important in producing these responses to milk. Nutritional deprivation alone, with or without the presence of an active maternal female, appears to be sufficient to produce ingestion. Behavioral activation, on the other hand, appears to require both nutritional deprivation and deprivation from a maternal female. The effect of maternal stimulation on later behavioral reactivity was not a function of the pups' opportunity to suckle. However, active maternal stimulation was more effective in preventing activation than was passive maternal stimulation (e.g., thermotactile and olfactory stimulation). Stimulation provided by an active, nonlactating mother was effective in preventing behavioral activation, but the effect was shortlived, lasting only $2 \mathrm{hr}$ after the pup was removed from the mother's care. This series of studies thus reveals that identified components of maternal separation have dissociable effects on appetitively motivated behaviors in infant rats. 
Rat pups less than 1 week old that have been deprived of food, maternal care, and the opportunity to suckle show dramatic behavioral activation in response to oral infusions of milk (Hall, 1979b). This activation consists of an increase in nondirected, general locomotion, including fragments of behaviors representing virtually the entire behavioral repertoire of pups, as well as specific suckling- and feeding-related behaviors like rooting, probing, mouthing, and licking. Activation is accompanied by vigorous ingestion of the infused diet. Nondeprived pups, on the other hand, are comparatively inactive and ingest little of the diet.

This behavioral phenomenon and similar forms of induced activation in infant rats (Hall, 1979a, b; Lithgow \& Barr, 1984; Moran, Schwartz, \& Blass, 1983b; Pedersen, Williams, \& Blass, 1982; Sullivan, Hofer, \& Brake, 1986; Terry \& Johanson, in press), have been the subject of recent investigation because of the possible relationship of activation of the operation of primitive reward and arousal systems. For example, a similar pattern of overt excitement in young rat pups has been elicited by rewarding brain stimulation (Lithgow \& Barr, 1984; Moran, Lew, \& Blass, 1981; Moran et al., 1983b) and this electrical stimulation has also been found to induce ingestion in young rats (Moran, Schwartz, \& Blass, 1983a). Others have suggested that behavioral activation may be necessary for learning to occur in some conditioning paradigms (Johanson, Hall, \& Polefrone, 1984). Thus, activation may represent the overt expression of affective or motivational functions at an early stage in pups' neural organization and the development, functions that are presumably maintained into adulthood but that become less obvious.

The particular deprivation-related processes that lead to the expression of behavioral activation in response to milk infusion in young pups are not yet understood. Our standard deprivation procedures have typically involved both removing the pups from normal maternal interaction as well as depriving them of all food and fluid. In such cases maternal deprivation and nutritional/hydrational deprivation were always confounded. Each component of deprivation could be making a contribution to later reactivity to milk infusions. It has been shown, for example, that deprivation from just the mother for short periods results in both behavioral and physiological changes in rat pups (activity levels, Hofer, 1981; heart rate and respiration rate, Hofer, 1973, 1975; ornithine decarboxylase activity, and growth hormone, Evoniuk, Kuhn \& Schanberg, 1979; sucking frequency, Brake \& Hofer, 1980). Conversely, the nutritional component of maternal deprivation alone has been found to be critical to other physiological effects of maternal deprivation (Hofer, 1973) and to basal activity levels (Moorecroft, Lytle, \& Campbell, 1973) and to activity levels during feeding (Phifer, Sikes, \& Hall, 1986). Similarly, nutritional state also influences general activity in adults (Campbell \& Lynch, 1969). Thus, the effects of deprivation are varied but incompletely described. The primary goal of the following experiments was to isolate and identify some of the deprivation-related factors responsible for pups' responsivity.

We attempted to dissociate the effects of nutritive and maternal deprivation on subsequent feeding behavior and behavioral activation in 6-day-old rat pups. By depriving pups with nonlactating "foster mothers," the pups could be provided with apparently normal maternal and suckling experiences, yet they would not receive milk. We found that nutritional deprivation alone was not sufficient to make pups reactive to milk infusions. Subsequent experiments investigated whether there were critical components of maternal presence, the absence of which leads to later feeding-induced 
activation. The relative contribution of suckling, the importance of active versus passive maternal care, and the duration of the suppression of activation exerted by previous maternal presence were each studied.

\section{General Methods}

\section{Subjects}

Subjects were progeny of Charles River CD strain rats. Pregnant females were housed in individual cages $(20 \times 24 \times 45 \mathrm{~cm})$ containing wood chip bedding. Water and Purina Lab Chow (\#5008) were provided ad libitum. The colony room was maintained at $21-24^{\circ} \mathrm{C}$, with $40-70 \%$ relative humidity, and was on a 14 : 10 hr light : dark cycle. Cages housing pregnant females were checked daily for births at approximately $1700 \mathrm{hrs}$ and pups found at that time were termed 0 days of age. At 2 days of age litters were culled to 10 pups each, with an equal number of males and females. All pups were 6 days old when tested.

\section{Deprivation Procedures}

Two groups of pups were common to each experiment: one group of nondeprived pups, which were housed with their mother until the time of testing, and a second group of incubator-deprived pups, which were deprived of all maternal care and the opportunity to suckle and receive milk. Incubator-deprived pups were housed individually in small styrofoam cups, without bedding, and placed in a warm $\left(32.5 \pm 1{ }^{\circ} \mathrm{C}\right)$, moist $(70-90 \%$ relative humidity) incubator (Isolette, AirShields, Inc.). They were removed from the mother 20 to $24 \mathrm{hr}$ before testing unless otherwise noted (see Experiment 3). Other groups of experimental pups were removed from their respective treatment conditions 10 to $15 \mathrm{~min}$ before testing. Their treatment conditions will be described in the individual experiments.

\section{Cannula Implantation}

The oral cannulas used for milk infusion were implanted 10 to $15 \mathrm{~min}$ before testing. The cannulas were made by heating one end of a $10-\mathrm{cm}$ piece of fine polyethylene tubing (PE-10, Clay Adams). As the end began to blister, it was pressed flat on a smooth surface, forming a small flange (see Hall, 1979b, for details). The cannula was implanted in the front of the pups' mouths with a fine stainlesssteel wire that had a half-circle bend at one end. The nonflanged end of the cannula was fitted over the straight end of the implantation wire, and the curved end of the wire was then inserted through the mouth into the soft tissue behind the lower incisors and in front of the base of the tongue. As the wire was pulled out through the lower jaw, the cannula was pulled into position in the front of the mouth. Milk infusions made at this position spill out of the pup's mouth unless the pup actively licks and swallows the fluid (Hall, 1979b). The implantation procedure required less than $10 \mathrm{sec}$, and pups appeared to habituate rapidly to the presence of the cannula. An anesthetic (such as ether) was not used because the anesthesia appears to cause greater distress than the implantation procedure itself. 


\section{Test Procedures}

We tested pups in clear, round plastic containers (12 $\mathrm{cm}$ in diameter) located inside a test incubator (maintained at $34^{\circ} \mathrm{C}$ ). The test incubator was constructed from a 57-lit glass aquarium covered with a roof of hinged Plexiglas panels, and it was warmed and humidified by circulating air over an aquarium heater $(100 \mathrm{~W})$ and a tray of water.

Just prior to testing, we removed pups from their deprivation/treatment conditions, implanted cannulas, emptied their bladders and bowels by gently stroking the anogenital region with a soft, wet, artist's brush, and weighed them to the nearest $0.001 \mathrm{~g}$. These procedures took 10 to $15 \mathrm{~min}$. Thus, there was never more than 15 min between removal from treatment condition and testing. After weighing, pups were placed in the test containers where testing began after a 2-min adaptation period during which behavioral observations (described below) and baseline activity measures were made.

At the end of the 2-min adaptation period, a 13-sec infusion of milk was made into pups' mouths. Identical infusions were made every 2 min for the remaining $10 \mathrm{~min}$, for a total of five infusions. Pups received milk at a rate slightly faster than they could swallow to avoid ceiling effects on intake. A total of $2.5 \%$ of the average nondeprived body weight of the pups was provided in five infusions of equal volume $(0.38 \mathrm{ml})$. Infusions were delivered to the oral cannulas through Micro-Renathane tubing (Type 040; Braintree Scientific, Inc.) from syringes driven by an infusion pump (Harvard Model 975) and were programmed by a timer. The diet was fresh, commercially available Half-and-Half (half cream, half milk). This milk has certain similarities to rat's milk (e.g., percentage of fat and water), although it is not an adequate diet for normal growth.

Following testing, pups were removed from their test containers, dried gently, and reweighed. Weight gain during the test accurately reflects milk intake because voiding pups before testing prevents weight loss through elimination during the test, and insensible losses for such a short period are slight. Intake was expressed as a percentage of the total volume infused.

\section{Behavioral Observations}

We observed and scored pups' behavior every $30 \mathrm{sec}$ throughout the test, using a rating system described by Hall (1979b). Three major behavioral items were recorded: (A) For every 30-sec interval, the level of general locomotor activity was rated. The 7-point rating scale for activity was as follows: $0=$ no movement, except for occasional twitches; 1 = slight movement of the head or paw, sustained for $5 \mathrm{sec}$; 2 = substantial movement of the head and paws, including grooming, but no locomotion; 3 = locomotion involving forelimbs only, often including rooting and probing, but with hindlimbs remaining motionless and usually serving as a pivot point; $4=$ clear and sustained locomotion (involving all limbs); $5=$ vigorous locomotion, often including rolling, kicking and wall-climbing; $6=$ an extreme, but occasionally observed version of 5, in which the pup tumbles about its test container for most of the 30 -sec interval, locomoting, rolling, probing, wall-climbing, and jumping. Activity score data is expressed as the numerical sum of the pup's behavior for the entire 12-min test. (B) Pups were scored in each interval for the occurrence of mouth- 
ing, i.e., obvious movement of the mouth and jaws sustained for at least $5 \mathrm{sec}$. (C) Pups were also scored for the occurrence of probing, which was indicated by repeated and vigorous vertical movement of the head with the neck flexed, bringing the snout and lips into contact with the floor, the corners, and occasionally the wall of the test container. Mouthing and probing data are expressed as the numerical sum of the pup's ratings ( 0 for no occurrence and 1 for an occurrence). Comparisons between two observers using this rating system have indicated good interobserver reliability (ranging from 0.8 to 0.95 , Pearson product-moment coefficient).

\section{Data Analysis}

We treated litters as the experimental unit throughout the experiments (Abbey \& Howard, 1973; Denenberg, 1977, 1984). A litter was tested at one age only, with either one or two pups (one of each sex) from a litter serving in a given condition, depending on the experimental design. When two pups from a litter received the same treatment, their intakes and activity measures were averaged to obtain a single value. Experimental conditions were balanced for sex. Overall treatment effects were evaluated with a randomized block ANOVA. Where appropriate, the least significant difference (LSD) test was used for post-hoc analysis of differences between specific treatment groups (Kirk, 1982).

\section{Experiment 1: Maternal Contributions to Milk-induced Activation}

The role of maternal deprivation in determining later behavioral activation was examined by placing pups with foster mothers that did not provide milk but did provide all other forms of maternal care. Pups' subsequent reactivity in milk-infusion tests could be compared to pups deprived of both nutrition and maternal care. Foster mothers had their own pups removed 1-2 weeks prior to testing. This period without pups was short enough that the dam still displayed clear maternal behavior and, as well, nipples were still distended and permitted suckling, yet, it was a long enough period that lactation had ceased (Rosenblatt \& Siegel, 1981). Thus, pups placed with a foster mother could suckle without receiving milk. This procedure put them in the same nutritive state as incubator-deprived controls, but they received, maternal experiences similar to those received by nondeprived pups.

\section{Methods}

Six litters were used in this experiment. Pups were removed from their mother at 5 days of age, then weighed and numbered. Two pups from a litter were then placed in each experimental condition: incubator-deprived, nondeprived, and foster-deprived. The number of pups with each female during the 24-hr deprivation period was maintained at 3 or 4 by using extra pups from the test litter. Periodic observations during the treatment period confirmed that foster mothers groomed, handled, and huddled over the pups, and that the pups were frequently attached to nipples and suckling. Absence of weight gain during the treatment period confirmed that foster mothers were not lactating (pups left with a foster mother actually lost slightly more weight than incubator-deprived pups). After 20-24 hr of the respective treatments, all pups had cannulas implanted and were tested as described in General Methods. 

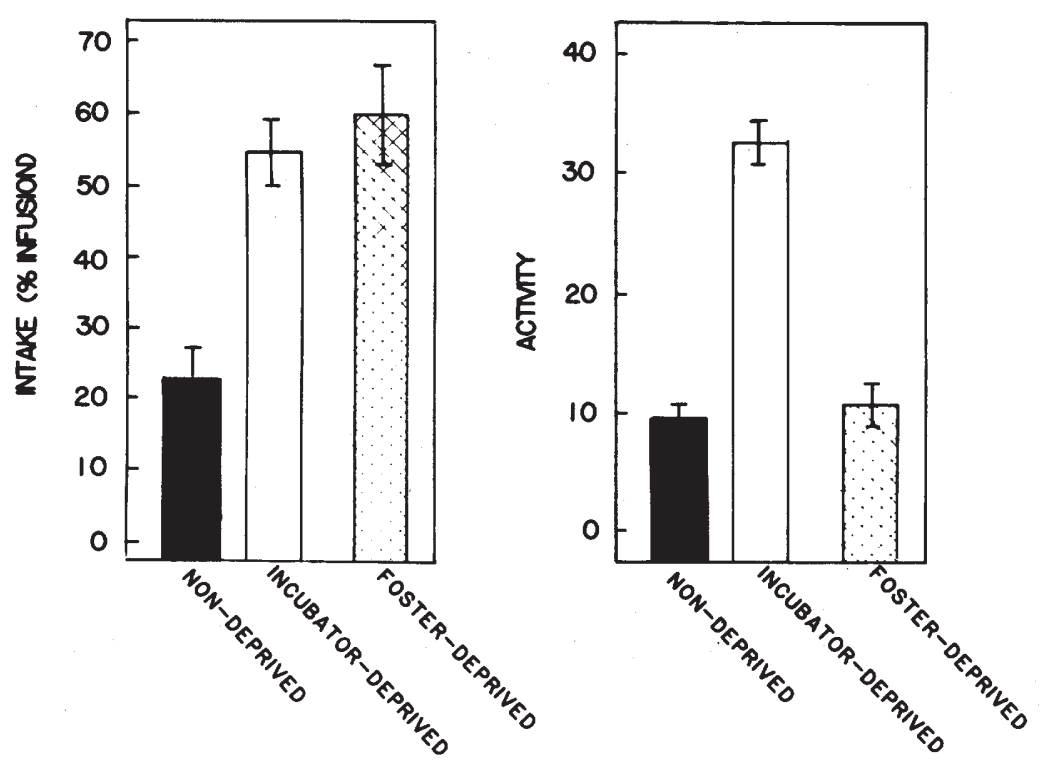

Fig. 1. (a) Mean intakes of incubator-deprived, nondeprived, and foster-deprived pups in Experiment 1, expressed as a percentage of the volume offered to the pup (final body weight initial body weight/volume infused). (b) Mean activity score of the pups in Experiment I. Error bars represent SEM.

\section{Results}

As expected, those pups that were nutritionally deprived, either in the incubator-deprived condition or in the foster-deprived condition, ingested significantly more milk than those pups which had received milk from their natural mother overnight [Figure 1a; Deprivation Main Effect, $F(2,10)=18.13, p<.01$ ]. Moreover, incubator-deprived pups showed high levels of behavioral activation when compared to nondeprived pups [Figure 1b; Deprivation Main Effect, $F(2,10)=$ $57.54, p<.01]$. However, pups kept with a foster mother overnight displayed significantly less behavioral activation than incubator-deprived pups (LSD test, $p$ $<.05)$. In fact, their activity scores were virtually identical to those of nondeprived pups. Similarly, incubator-deprived pups showed considerably more probing behavior than either of the other groups [Table 1; Deprivation Main Effect, $F(2,10)$ $=9.99, p<.01]$.

Although incubator-deprived pups also showed the most mouthing behavior, pups deprived with a foster mother still mouthed nearly twice as much as nondeprived pups [Table 1; Deprivation Main Effect, $F(2,10)=34.20, p<.01$; LSD test for difference between foster- and nondeprived pups, $p<.05]$. The foster-deprived pups were simply less active during ingestion.

Exposure to a nonlactating foster mother also resulted in lower activity during the preinfusion adaptation period [activity score of incubator-deprived pups was $2.96 \pm 0.7$ while nondeprived and foster-deprived activity scores were $1.2 \pm$ 0.6 and $0.9 \pm 0.4$, respectively; Deprivation Main Effect, $F(2,10)=4.42, p<.05$ ]

Maternal deprivation thus appears to be necessary for behavioral excitement 


\begin{tabular}{|c|c|c|}
\hline & Mouthing & Probing \\
\hline Incubator-deprived & $\begin{array}{l}17.0 \\
(0.9)\end{array}$ & $\begin{array}{c}7.5 \\
(1.9)\end{array}$ \\
\hline Nondeprived & $\begin{array}{c}6.7 \\
(1.5)\end{array}$ & $\begin{array}{c}0.4 \\
(0.3)\end{array}$ \\
\hline Foster-deprived & $\begin{array}{l}12.0 \\
(1.3)\end{array}$ & $\begin{array}{c}1.6 \\
(0.4)\end{array}$ \\
\hline
\end{tabular}

in response to milk infusion as well as for heightened general activity in the absence of milk infusions. However, the treatments in; this experiment do not reveal whether the opportunity to suckle (present with foster mothers as well as normal mothers), or some other feature of maternal stimulation is the critical feature in preventing the occurrence of behavioral activation. In the next experiment, the effect of maternal care with and without nonnutritive suckling was assessed.

\section{Experiment 2: Suckling and Later Responsiveness}

The importance of suckling to later behavioral activation was tested by placing pups with a virgin female that had been rendered maternal (sensitized) by exposure to young pups for several days prior to the experiment (Rosenblatt \& Siegel, 1981; Rosenblatt, 1967). Although this exposure induced maternal behavior (e.g., huddling, licking, stroking, retrieving; see Rosenblatt \& Siegel, 1983), the female's nipples remained undeveloped and undistended and did not allow pups to attach to nipples and suckle. This manipulation thus provided a means of comparing maternal care with suckling to maternal care without suckling (by comparing foster-deprived to virgin-deprived pups) with regard to effects on activation.

\section{Methods}

Virgin females were rendered maternally responsive by exposure to 2-4-dayold pups daily for $1-2$ weeks. Females were accepted for use in this study only when they were observed to huddle over, lick, and groom the pups consistently. Pups from 6 litters served in this experiment. Experimental procedures were identical to those employed in Experiment 1, with the addition of the maternally-behaving virgin group. Thus, the experiment included: incubator-deprived pups, nondeprived pups, pups left with a foster mother (foster-deprived), and pups left with a maternal virgin female (virgin-deprived). Maternal behavior of foster mothers and virgin females during the treatment period was confirmed by periodic observations. No pup was ever observed to be suckling from a virgin female. Weight loss by pups in both of these groups was again slightly greater than that of incubator-deprived pups, demonstrating that they did not receive nutrient during the treatment period. 

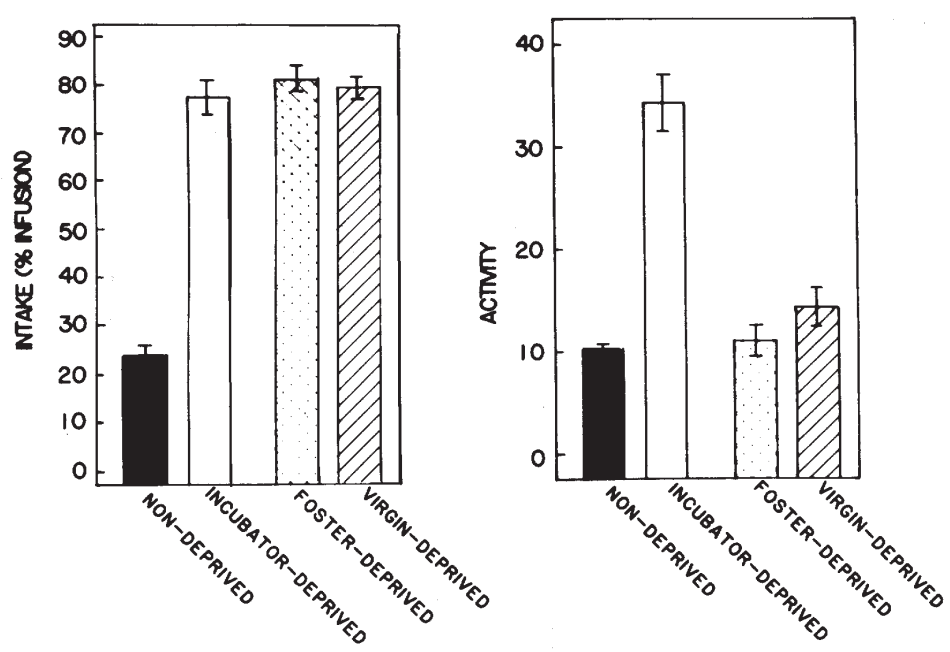

Fig. 2. (a) Mean intakes of incubator-deprived, nondeprived, foster-deprived, and virgin-deprived pups in Experiment 2, expressed as a percentage of the volume offered to the pup (final body weight — initial body weight/volume infused). (b) Mean activity score of the pups in Experiment 2. Error bars represent SEM.

\section{Results}

The results of this experiment are consistent with those of Experiment 1. Behavioral activation was seen only in pups that were deprived of maternal stimulation [Deprivation Main Effect, $F(3,15)=38.1, p<.01$; Figure 2b], while intake was contingent upon nutritional deprivation [Deprivation Main Effect, $F(3,15)=$ $107.9, p<.01$; Figure $2 \mathrm{a}]$. Further, there were no significant differences in any behavior measured between pups cared for by virgin females and those cared for by foster mothers. Pups tended by maternally-responsive, virgin females ingested amounts equal to those of deprived pups (LSD, $p>.05$ ), yet they showed behavioral patterns typical of their foster- and nondeprived littermates.

Food deprivation resulted in increased mouthing during testing [Table 2; Deprivation Main Effect, $F(3,15)=75.98, p<.01$ ], but the presence of maternal behavior, provided by a natural mother, foster mother, or virgin female, was sufficient to prevent the expression of probing [Table 2; Deprivation Main Effect, $F(3$, $15)=14.8, p<.01]$.

TABLE 2. Mean Mouthing and Probing Scores ( \pm SEM) of Pups in the Different Deprivation Conditions in Experiment 2.

\begin{tabular}{lcc}
\hline & Mouthing & Probing \\
\hline Incubator-deprived & 17.9 & 11.1 \\
& $(1.1)$ & $(1.6)$ \\
Nondeprived & 6.0 & 0.3 \\
& $(0.4)$ & $(0.2)$ \\
Foster-deprived & 14.5 & 3.1 \\
& $(1.1)$ & $(1.1)$ \\
Virgin-deprived & 16.6 & 5.1 \\
& $(0.5)$ & $(1.1)$ \\
\hline
\end{tabular}


Activity levels during the preinfusion adaptation were also low in each group receiving maternal care [e.g., $3.1 \pm 0.5$ vs. $0.6 \pm 0.2,0.9 \pm 0.4,1.3 \pm 0.5$ for incubator-deprived versus nondeprived, foster-deprived, and virgin-deprived, respectively; Deprivation Main Effect, $F(3,15)=7.07, p<.05]$. Since the only obvious difference between the virgin females and foster mothers is the capacity to afford nonnutritive suckling, we conclude that suckling, in the presence of active maternal care, is not necessary to prevent pups' behavioral activation, although it might be sufficient to produce this effect in the absence of other components of maternal stimulation.

\section{Experiment 3: Active Versus Passive Maternal Contributions}

Lack of opportunity to suckle does not appear crucial for later reactivity to milk, yet it is not clear whether activation depends on deprivation of the active or passive forms of stimulation that accompany the mother's presence. Passive stimuli include the mother's odors, warmth, and fur. These provide specific olfactory, thermal, and tactile information to the pups. Here we tested the effectiveness of such stimuli, without the mother's active manipulation of pups, by placing pups with anesthetized mothers. These anesthetized mothers had their pups removed shortly before the deprivation treatment, so their nipples were readily suckled; however, milk letdown was blocked by the anesthesia (Lincoln, Hill, \& Wakerly, 1973). The duration of maternal exposure in this experiment was also reduced $(6 \mathrm{hr})$ to provide an assessment of shorter periods of maternal stimulation in influencing milk-elicited activation.

\section{Methods}

Pups from six litters served in this experiment. After $18 \mathrm{hr}$ of incubator deprivation and $6 \mathrm{hr}$ before the feeding test, pups were placed into maternal treatment conditions. Thus, rather than a 24-hr period of maternal exposure as in Experiments 1 and 2, pups received only $6 \mathrm{hr}$ (during 24) of maternal stimulation. In a given experimental run, two pups ( 1 male, 1 female) from each of two test litters experienced one of five experimental conditions: incubator-deprived (24 hr), 6-hr-lactating (with a normal, lactating-mother for $6 \mathrm{hr}$ ), 6-hr foster-deprived (with a foster mother for 6 $\mathrm{hr}$ ), and two separate 6-hr treatment groups on the anesthetized mother, one that received the opportunity to suckle (anesthetized-ventral) and one that did not (anesthetized-dorsal). The mother was anesthetized (Ethyl Carbamate; $0.2 \mathrm{~g} / \mathrm{ml}$ in distilled water; $7 \mathrm{ml} / \mathrm{kg}$ body weight), placed across the width of the standard housing cage, and a cardboard partition, cut to conform to the mother's flank, was taped in position to divide the area of her ventrum from that of her back. The first group, placed on one side of the partition, had restricted access to the mother's ventral side and nipples, and the second, placed on the other side, had access only to the mother's dorsal side. Saliva from the mother's mouth was applied to her nipples with a small paint brush in order to facilitate the initiation of suckling by pups on her ventral side (Pedersen \& Blass, 1982; Teicher \& Blass, 1976). The anesthetized mothers were checked hourly to ensure that the mother was anesthetized, that the pups in the suckling condition were attached to nipples, and that pups on a dam's dorsal side 


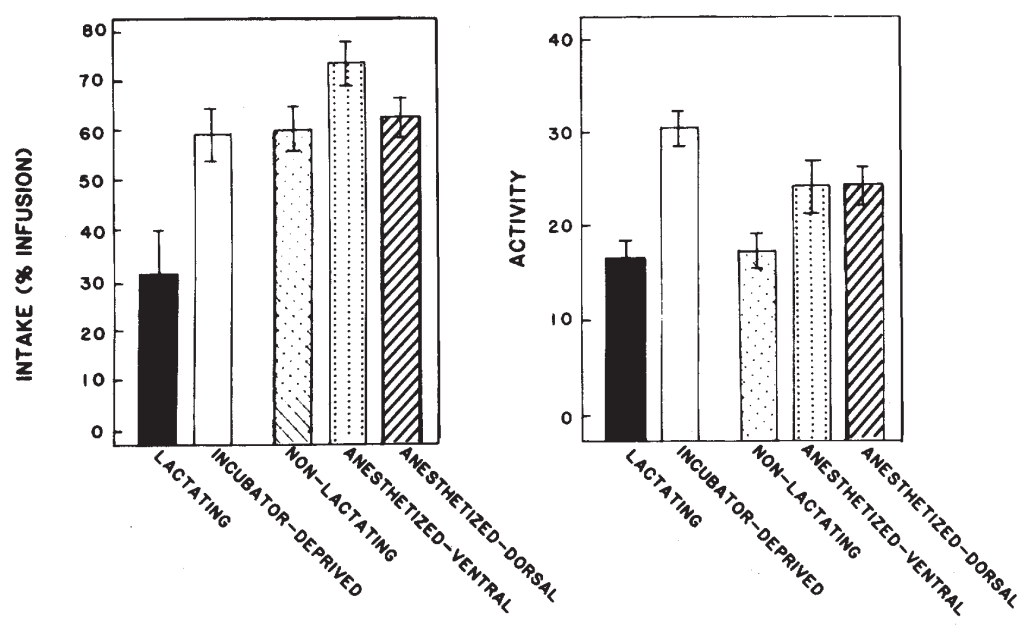

Fig. 3. (a) Mean intakes of incubator-deprived, nondeprived (6 hr with a lactating female), foster-deprived ( $6 \mathrm{hr}$ with a nonlactating female), and deprived on the ventral or dorsal side of an anesthetized mother (for $6 \mathrm{hr}$ ) in Experiment 3, expressed as a percentage of the volume offered to the pup (final body weight -initial body weight/volume infused). (b) Mean activity score of the pups in Experiment 3. Error bars represent SEM.

were close enough to her to receive the intended olfactory and thermotactile stimulation. Absence of weight gain in the pups on the ventral side confirmed that milk letdown had been blocked. The mother of one litter served as the lactating mother, the mother from the other litter as the anesthetized mother. Preliminary analysis of the dependent measures indicated no differential effect of a pup's own mother being its treatment mother. At the end of the 6-hr treatment period, pups were tested as described in General Methods.

\section{Results}

All pups that were nutritionally deprived ingested significantly more than the 6-hr-lactating-mother group [Figure 3a; Deprivation Main Effect, $F(4,20)=8.75$, $p<.01]$. As in Experiments 1 and 2, pups in the 6-hr-lactating and foster-deprived conditions showed significantly less activation in response to milk infusions than incubator-deprived pups [Figure 3b; Deprivation Main Effect, $F(4,20)=8.56$, $p<.01]$. Activity scores for both groups of pups with the anesthetized dam were midway between those for the incubator-deprived and 6-hr-lactating groups (the anesthetized groups were significantly less active than incubator-deprived and significantly more active than pups that were with a normal-lactating mother; LSD test, $p<. .05$ ). These data indicate that, although pups' interaction with thermotactile and olfactory stimulation, with or without suckling, is capable of decreasing behavioral activation, it is less effective than stimulation from an active maternal female. Thus, active maternal behavior must be responsible for the comparatively low level of milk reactivity seen in 6-hr-lactating and foster-deprived pups.

As in previous experiments, activity during the adaptation period was affected in the same manner as activation induced by milk infusions [although here the differences did not reach statistical significance; Deprivation Main Effect, $F(4$, 20) $=1.4]$. 
TABLE 3. Mean Mouthing and Probing Scores ( \pm SEM) of Pups in the Different Deprivation Conditions in Experiment 3.

\begin{tabular}{lcc}
\hline & Mouthing & Probing \\
\hline Incubator-deprived (24 hr) & 17.3 & 11.2 \\
& $(0.7)$ & $(1.9)$ \\
Nondeprived (6 hr) & 8.8 & 3.5 \\
& $(1.9)$ & $(1.1)$ \\
Foster-deprived (6 hr) & 14.5 & 5.0 \\
& $(1.0)$ & $(1.2)$ \\
Anesthetized-ventral (6 hr) & 15.5 & 5.5 \\
& $(1.1)$ & $(2.1)$ \\
Anesthetized-dorsal (6 hr) & 16.6 & 9.3 \\
& $(1.1)$ & $(0.9)$ \\
\hline
\end{tabular}

With respect to specific behaviors, mouthing (as in Experiments 1 and 2) paralleled the pattern of intake data. Only probing showed a significant difference between pups exposed to the ventral and dorsal sides of the anesthetized mother [Table 3; Deprivation Main Effect, $F(4,20)=5.79, p<.01$ ]. Pups previously exposed to the dam's dorsal side probed more (LSD test, $p<.05$ ). The opportunity of pups on the ventral side to search for, find a nipple, and suckle appeared to reduce probing in a somewhat different manner than mere exposure to the mother.

Comparisons of these data to those of Experiments 1 and 2 indicate that maternal stimulation needs to be present for more than $6 \mathrm{hr}$ to prevent completely the expression of milk-elicited activation. Although the activity scores for 6-hr treatment with lactating and foster mothers were significantly lower than those for the incubator-deprived and anesthetized-deprived pups in this experiment, they were higher than scores for pups that had 24-hr exposure to either their natural or a foster mother (compare to Figures 1b, 2b). Note too, that $6 \mathrm{hr}$ with a lactating mother did not reduce food intake to nondeprived levels (Figure 3a vs. Figures 1a, 2a).

\section{Experiment 4: Duration of the Maternal Effects}

In the final experiment, the duration of the suppressive effects of maternal exposure on behavioral activation was assessed. How long do pups remain inactive to milk infusions after experience with an active mother? And how does the duration of the maternal effect compare in nutritionally-deprived and non-nutritionally-deprived pups? Groups of nondeprived, incubator-deprived, and foster-deprived pups were again employed but they were tested at a variable delay after the conclusion of the experimental manipulations.

\section{Methods}

Six litters were used in this experiment. Within each litter, three pups each were left 20-24 hr in either the incubator-deprived, nondeprived, or foster-deprived condition. After removal from the respective treatments, one pup from 


\begin{tabular}{lcc} 
TABLE 4. Mean Intake (Expressed as a Percent- \\
age of the Volume of Milk Offered) and Mouthing \\
Scores ( \pm SEM) of Pups in the Different Depriva- \\
tion and Delay Conditions of Experiment 4. \\
\hline \multicolumn{3}{c}{ Intake } \\
\hline \multicolumn{3}{c}{ Mouthing } \\
Incubator-deprived & \\
15 min & 66.8 & 16.0 \\
& $(7.0)$ & $(1.2)$ \\
45 min & 64.0 & 16.4 \\
& $(7.1)$ & $(1.4)$ \\
120 min & 60.7 & 16.7 \\
& $(11.1)$ & $(1.1)$ \\
Nondeprived & & \\
15 min & 24.2 & 3.8 \\
& $(10.9)$ & $(1.5)$ \\
45 min & 26.2 & 4.6 \\
& $(8.5)$ & $(1.4)$ \\
120 min & 27.5 & 5.7 \\
& $(5.5)$ & $(1.4)$ \\
Foster-deprived & & \\
15 min & 67.7 & 10.8 \\
& $(11.8)$ & $(1.4)$ \\
45 min & 61.0 & 11.3 \\
& $(14.1)$ & $(1.3)$ \\
120 min & 69.2 & 14.6 \\
& $(9.0)$ & $(1.6)$ \\
\hline & &
\end{tabular}

each of the experimental conditions had a cannula installed, and the three pups were given our standard infusion test simultaneously. Thus, pups tested in this first trial experienced essentially a 15-min delay (the time required for cannula installation, voiding, weighing, and test chamber adaptation). Identical tests were then performed at delays of 45 and 120 min after removal from treatment conditions. Pups were placed in a standard incubator during these delay periods.

\section{Results}

After a 15-min delay, pups in each condition behaved as in Experiment 1. Nondeprived and foster-deprived pups were significantly less active than incubator-deprived pups (LSD test, $p<.01$ ), while both incubator-deprived and fosterdeprived pups ingested significantly greater amounts than their nondeprived littermates [Table 4; Intake, Deprivation Main Effect, $F(2,40)=30.71, p<.01$; Figure 4a: Activity, Deprivation Main Effect, $F(2,40)=116.72, p<.01]$. The same was true $45 \mathrm{~min}$ after removal from the deprivation conditions. By $2 \mathrm{hr}$ after removal, however, pups kept with foster mothers overnight displayed significant increases in general activation and probing behavior [Figure $4 \mathrm{a}$ and $\mathrm{b}$; Activity and Probing: Deprivation $\times$ Delay Interaction, $F(4,40)=2.67, p<.05$ and $3.85, p<.01$, respectively]. In fact, their activity scores were intermediate between those of nondeprived and incubator-deprived pups, and probing (which seems to be closely correlated with activation in these studies) nearly equalled that of incubator-deprived pups. The delay of $2 \mathrm{hr}$ failed to enhance ingestion significantly in any condition 


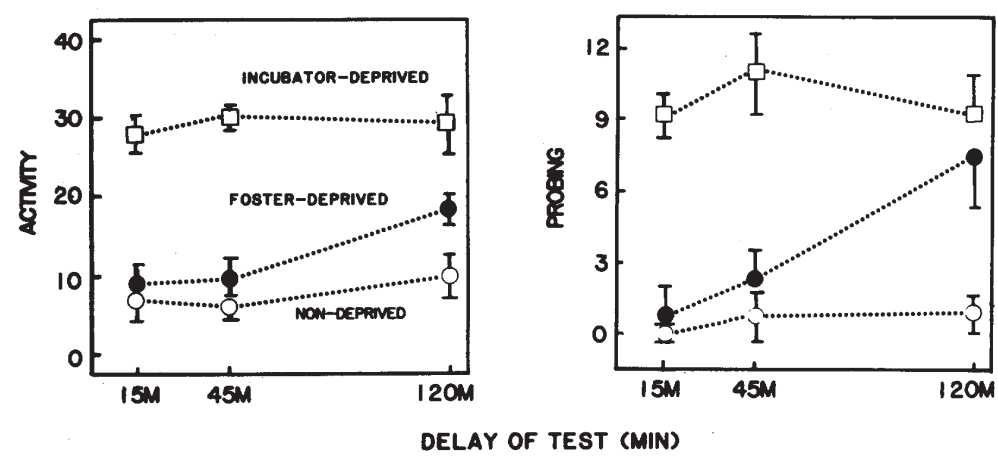

Fig. 4. (a) Mean activity score of incubator-deprived, nondeprived, and foster-deprived pups as a function of the delay from their removal from the deprivation treatment to testing $(15,45$, or 120 min) in Experiment 4. (b) Mean probing score of pups in Experiment 3 as a function of the delay from their removal from the deprivation treatment to testing. Error bars represent SEM.

(Deprivation $\times$ Delay Interaction, ns), and only significantly affected activity and probing in the foster-deprived pups (LSD test, $p<.05$ ). Thus, although the effects of having been with the foster mother are indistinguishable from those of the normally lactating mother immediately after the pups' removal, the foster mother's influence begins to diminish within two hours after the pups' removal from her care. It seems likely that the increase in behavioral activation seen in foster-deprived pups, as a function of the time to testing, is a result of their nutritionallydeprived status. In nutritionally-deprived pups the recency of the maternal stimulation plays an important role in the degree of behavioral activation in response to oral infusions of milk. In contrast, a period of maternal absence for non-nutritively-deprived pups did not lead to activation.

\section{Discussion}

One appeal of developmental analysis is that organizational characteristics of behavioral systems are frequently revealed in new or different perspectives. Infants, for example, often display behaviors that are internalized, suppressed, or lost in older animals. The processes sub serving these behaviors are thereby made more available for analysis early in life. The behavioral activation of young rat pups is one example. It appears to be a correlate, if not the expression, of early reward or arousal. Its representation in the infant is generalized and overt but then disappears with age.

That activation may be related to reward is suggested by studies of early appetitive learning. Infant rats will perform an operant task to receive oral milk infusions (Johanson \& Hall, 1979) and these oral infusion always elicit heightened activity. Pups also show behavioral activation to a neutral odor after it has been paired repeatedly with oral milk infusions (Johanson, Hall, \& Polefrone, 1984). The occurrence of behavioral activation appears to be necessary for both types of appetitive learning to take place. Other studies indicate that activation may be sufficient for learning to occur. For example, activating pups by gently stroking them with a soft brush has recently been shown to support a learned preference to an odor (Sullivan, Hofer, \& Brake, 1986). Moreover, convergent evidence on the 
role of activation in reward has been provided by Moran and his colleagues, who showed that electrical stimulation of the medial forebrain bundle (MFB) would reward paddle probing by young pups (Moran, Lew, \& Blass, 1981). They also demonstrated that MFB stimulation in young pups produced a behavioral activation very similar to that seen with milk infusions (Moran et al., 1983b); and, like the response to milk, activation diminished and behavior became more focused or specific as pups grew older. Thus, activation appears to be at least a correlate, if not a representation of, neural reward processes similar to those seen in adults. It should be noted that there are differences between milk-induced activation and MFB stimulation-induced activation, the most important being that maternal and nutritional deprivation are not necessary for behavior induced by MFB stimulation. MFB stimulation appears to have direct access to activational systems.

In the present experiments, we evaluated the characteristics of "deprivation" that contribute to this activation, realizing that activation may represent general arousal and reinforcement processes. We also assessed more specific components of pups' reactivity: in "probing," which was in most cases correlated with activity, but may in fact be a primitive exploratory response, and "mouthing," which was closely related to ingestion. We found that pups will ingest milk without apparent activation. Thus early consummatory responding can be separated from activation. Ingestion seems to only require nutritional deprivation, while sensory and nutritional deprivation are necessary for behavioral activation. This behavioral separation indicates that, to the degree that either activation or ingestion are rewarding, they may represent reward systems with separable substrates. Thus, starting early in development, it may be possible to identify multiple components of reward.

\section{Tactile and Kinesthetic Stimulation}

Maternal deprivation was required to produce the behavioral reactivity to milk infusions, though it had no effect on intake. The failure of maternal stimulation to block or attenuate ingestion suggests that this ingestive system is under nutritive (or gastric, see Phifer et al., 1986) controls. This lack of effect on independent ingestion can be contrasted to the effect of experience with a foster mother on intake during suckling (Cramer \& Blass, 1985). Suckling, interestingly, appears less constrained by nutritive factors (Hall \& Williams, 1983). Here deprivation of suckling per se was not necessary (Experiment 2) for activation, and there was no difference in activity score between the two sets of pups on an anesthetized dam: one that had the opportunity to suckle and one that did not (Experiment 3). Moreover, both groups of pups left with an anesthetized dam were significantly less active than incubator-deprived controls, indicating that the mother's passively emitted thermotactile and olfactory stimuli, and the manner in which pups interacted with them, could partially reduce the otherwise high levels of activation. However, pups' interaction with an active mother was most effective in preventing later behavioral activation. The passive cues emitted by the mother were not nearly as effective as a conscious and behaving mother. Thus, the mother's major effect on behavioral activation in young pups requires her to interact with them, although the critical component of this interaction remains unknown. 


\section{Nutritive Factors}

In each condition in which pups showed behavioral activation in response to oral infusions, they were also nutritionally deprived. Thus, nutritional deprivation appears, along with maternal deprivation, to be a necessary condition for later reactivity. This point is supported by other studies in which deprived pups (both maternally and nutritionally deprived) that had received gastric preloads failed to show subsequent behavioral activation to oral milk infusions (Hall \& Bruno, 1984; Phifer et al., 1986). The results reported by Phifer et al. suggested that the effect of gastric loads may be almost exclusively on gastric fill and not on nutritive postgastric or metabolic mechanisms. The role of nutritional deprivation was also revealed in Experiment 4, in which it was found that the effects of maternal interaction wore off for nutritionally-deprived pups, though nondeprived pups did not become more active even after 2-hr separation from the mother. Maternal deprivation was thus not sufficient for activation.

\section{Maternal Separation}

This study becomes one of a number of investigations demonstrating multiple maternal separation effects on developing rat pups. Such effects can be behavioral (Hofer, 1973, 1981; Moorecroft et al., 1973) and physiological (Hofer, 1973, 1975; Evoniuk et al., 1979), and they appear to be regulated by different components of maternal behavior. For example, heart rate is influenced by gastric fill (Hofer, 1973); behavioral activity in 2-week-old pups is affected by maternal behavior and handling (Hofer, 1973, 1975, 1981); and ornithine decarboxylase levels can be influenced by a very specific form of grooming of pups by the mother (Evoniuk et al., 1979). Suppression of activation as a result of maternal care appears to be due not to the passive characteristics of the mother, but to the mother's interaction with her pups (or perhaps the behaviors induced in pups by maternal stimulation). Suckling per se did not appear to be a major factor in decreasing pups' general behavioral reactivity during feeding. However, with inactive anesthetized mothers there was some indication of differential probing behavior by pups that had the opportunity to suckle (Experiment 3). Thus, we conclude that an active maternal presence (e.g., huddling over, licking, stroking, picking up the pups, and stimulating interaction) is probably the crucial determinant of whether or not pups will become reactive to feeding (though vestibular stimulation does not attenuate spontaneous hyperactivity in 15-day-old rats; Hofer, 1981). Earlier unpublished studies in our laboratory are consistent with these results; we found that depriving pups with either a thalectomized or nipple-ligated mother resulted in low levels of behavioral activation.

We have not isolated any specific maternal behavior(s) responsible for these effects, and indeed, the effect of several aspects of maternal stimulation may be additive. In addition, while the focus of this paper has been the reactivity to milk infusions, it is clear that young pups' basal activity levels are also influenced by maternal factors as indicated by the differences in activity in the preinfusion periods of our tests.

\section{Summary}

The results of these experiments illustrate the importance of short-term maternal stimulation in shaping pups' ongoing environmental responsiveness. They 
also reinforce other demonstrations of the important distinctions between different aspects of the effects of maternal presence or separation (Hofer, 1978). In the presence of sensory/maternal stimulation, nutritional deprivation alone is insufficient to trigger the behavioral activation system, a system that may be related to one type or component of reward. Ingestion appears to be solely a function of nutritional deprivation. Thus, several distinct controls contribute to appetitive function in young rat pups, and these controls may be continuous with a multi-component reward system in adults.

\section{Notes}

We would like to thank D. Kucharski and C. Phifer for helpful suggestions on the manuscript, and E. Kenny and K. McCall for preparing the figures. This research was supported by NICHD Grant HD-17457 and HD-17458 to W. G. Hall.

\section{References}

Abbey, H., and Howard, E. (1973). Statistical procedures in developmental studies on species with multiple offspring. Dev. Psychobiol., 16: 329-336.

Brake, S. C., and Hofer, M. A. (1980). Maternal deprivation and prolonged suckling in the absence of milk alter the frequency and intensity of suckling responses in neonatal rat pups. Physiol. Behav., 24: 185-189.

Campbell, B. A., and Lynch, G. S. (1\%9). Cortical modulation of spontaneous activity during hunger and thirst. J. Comp. Physiol. Psychol., 67: 15-22.

Cramer, C. P., and Blass, E. M. (1985). Nutritive and nonnutritive determinants of milk intake of suckling rats. Behav. Neurosci., 99: 578-582.

Denenberg, V. H. (1977). Assessing the effects of early experience. In R. D. Myers (ed.), Methods in Psychobiology, Vol. 3. New York: Academic Press.

Denenberg, V. H. (1984). Some statistical and experimental considerations in the use of the analysis-of-variance procedure. Am. J. Physiol., 246: R403-R408.

Evoniuk, G. E., Kuhn, C. M., and Schanberg, S. M. (1979). The effect of tactile stimulation on serum growth hormone and tissue ornithine decarboxylase activity during maternal deprivation in rat pups. Comm. Psychopharmacol., 3: 363-370.

Hall, W. G. (1979a). Feeding and behavioral activation in infant rats. Science, 190: 1313-1315.

Hall, W. G. (1979b). The ontogeny of feeding in rats. I. Ingestive and behavioral responses to oral infusions. J. Comp. Physiol. Psychol., 93: 977-1000.

Hall, W. G. (1985). What we know and don't know about the development of independent ingestion in rats. Appetite, 6: 333-356.

Hall, W. G., and Bruno, J. P. (1984). Inhibitory controls of ingestion in 6-day-old rat pups. Physiol. Behav., 32: 831-841.

Hall, W. G., and Williams, C. L. (1983). Suckling isn't feeding, or is it? A search for developmental continuities. Adv. Study Behav., 13: 218-254.

Hofer, M. A. (1973). The role of nutrition in the physiological and behavioral effects of early maternal separation on infant rats. Psychosom. Med., 35: 350-359.

Hofer, M. A. (1975). Studies on how early maternal separation produces behavioral change in young rats. Psychosom. Med. 37: 245-264.

Hofer, M. A. (1978). Hidden regulatory processes in early social relationships. In P. P. G. Bateson and P. H. Klopfer (eds.), Perspectives in Ethology, Vol. 3: New York: Plenum Press.

Hofer, M. A. (1981). Parental contributions to the development of their offspring. In D. I. Gubernick 
and P. H. Klopfer (eds.). Parental Care in Mammals. New York: Plenum Press.

Johanson, I. B., and Hall, W. G. (1979). Appetitive learning in 1-day-old rat pups. Science, 205: 419-421.

Johanson, I. B., and Hall, W. G. (1980). The ontogeny of feeding in rats: III. Thermal determinants of early ingestive behavior. J. Comp. Physiol. Psychol., 94: 977-992.

Johanson, I, B., and Hall, W. G, (1982). Appetitive conditioning in neonatal rats: Conditioned orientation to a novel odor. Dev. Psychobiol., 15: 379-397.

Johanson, I. B., Hall, W. G., and Polefrone, J. M. (1984). Appetitive conditioning in neonatal rats: Conditioned ingestive responding to stimuli paired with oral infusions of milk. Dev. Psychobiol., 17: 357-381.

Kirk, R. E. (1982). Experimental Design: Procedures for the Behavioral Sciences. Belmont, CA: Brooks/Cole.

Lincoln, D. W., Hill, A., and Wakerley, J. B. (1973). The milk-ejection reflex of the rat: An intermittent function not abolished by surgical levels of anesthesia. J. Endocrinol., 57: 459-476.

Lithgow, T., and Barr, G. A. (1984). Self-stimulation in 7- and 100-day-old rats. Behav. Neurosci., 98: 479-486.

Moorcroft, W. H., Lytle, L. D., and Campbell, B. A. (1973). Ontogeny of starvation-induced behavioral arousal in the rat. J. Camp. Physiol. Psychol., 75: 50-67.

Moran, T. H., Lew, M. F., and Blass, E. M. (1981). Intracranial self-stimulation in 3-day-old rats. Science, 214: 1366-1368.

Moran, T. H., Schwartz, G. J., and Blass, E. M. (1983a). Stimulation-induced ingestion in neonatal rats. Dev. Brain Res., 7: 197-204.

Moran, T. H., Schwartz, G. J., and Blass, E. M. (1983b). Organized behavioral responses to lateral hypothalamic electrical stimulation in infant rats. J. Neurosci., 3: 10-19.

Pedersen, P. E., and Blass, E. M. (1982). Prenatal and postnatal determinants of the 1st suckling episode in albino rats. Dev. Psychobiol., 15: 349-355.

Pedersen, P. E., Williams, C. L., and Blass, E. M. (1982). Activation and odor conditioning of suckling behavior in 3-day-old albino rats. J. Exp. Psychol.: Anim. Behav. Proc., 8: 329-341.

Phifer, C. B., Sikes, C. R., and Hall, W. G. (1986). Ingestive controls in 6-day-old rat pups: Termination of intake by gastric fill alone. Am. J. Physiol., 250: R807-R814.

Rosenblatt, J. S. (1967). Nonhormonal basis of maternal and nonmaternal behavior in the rat. Science, 156: 1512-1514.

Rosenblatt, J. S., and Siegel, H. I. (1981). Factors governing the onset and maintenance of maternal behavior among nonprimate mammals. The role of hormonal and nonhormonal factors. In D. J. Gubernick and P. H. Klopfer (eds.), Parental Care in Mammals. New York: Plenum Press.

Rosenblatt, J. S., and Siegel, H. I. (1983). Physiological and behavioural changes during pregnancy and parturition underlying the onset of maternal behaviour in rodents. In R. W. Elwood (ed.), Parental Behaviour of Rodents. Chichester: Wiley \& Sons.

Sullivan, R., Hofer, M. A., and Brake, S. C. (1986). Olfactory-guided orientation in neonatal rats is enhanced by a conditioned change in behavioral state. Dev. Psychobiol., 19: 615-623.

Teicher, M. H., and Blass, E. M. (1976). Suckling in newborn rats: Eliminated by nipple lavage, reinstated by pup saliva. Science, 193: 422-425.

Terry, L. M., and Johanson, I. B. (in press). Olfactory influences on the ingestive behavior of infant rats. Dev. Psychobiol. 